\title{
HABITAR CASARÕES OCUPADOS NO CENTRO HISTÓRICO DE SALVADOR, BAHIA, BRASIL: velhos cortiços e novas experiências e direitos
}

\author{
Urpi Montoya Uriarte* (https://orcid.org/0000-0002-8135-7559)
}

\begin{abstract}
O objetivo deste artigo é descrever, analisar e refletir sobre uma modalidade de moradia que vem adquirindo progressiva importância quantitativa e qualitativa na cidade de Salvador (Bahia, Brasil) e em seu centro histórico (CHS). Trata-se da ocupação de casarões e prédios por pessoas pobres, ligadas aos movimentos Sem Teto. O trabalho de campo etnográfico, realizado junto a seis ocupações, permitiu-me chegar a algumas conclusões que apresento neste trabalho: 1) algumas ocupações são uma versão atualizada dos antigos cortiços do CHS, com problemas que agravam ainda mais sua situação; 2) a maior parte delas corresponde a ensaios de uma nova forma de habitar que representa uma experiência rica de autogestão e liderança feminina; 3) a centralidade é um valor essencial para os trabalhadores precarizados e vulneráveis que habitam desde o século XIX o centro da cidade, valor que passa a ser atualmente reivindicado, em discursos e (ou) práticas, como o direito à centralidade.
\end{abstract}

Palavras-chave: Ocupações. Centro Histórico de Salvador (CHS). Cortiços. Formas de habitar. Centralidade.

O objetivo deste artigo é descrever, ta uma experiência rica de autogestão e lideanalisar e refletir sobre uma modalidade de rança feminina; 3) a centralidade é um valor moradia que vem adquirindo progressiva importância quantitativa e qualitativa na cidade de Salvador e em seu centro histórico (CHS). Trata-se da ocupação de casarões e prédios por pessoas pobres, majoritariamente negras, ligadas aos movimentos Sem Teto. O artigo resulta de trabalho de campo etnográfico realizado junto às moradoras de seis ocupações ${ }^{1} \mathrm{e}$ permitiu-me chegar a algumas conclusões que apresento a seguir: 1) algumas ocupações são uma versão atualizada dos antigos cortiços do CHS, com problemas que agravam ainda mais sua situação; 2) a maior parte delas são ensaios de uma nova forma de habitar que represen-

* Universidade Federal da Bahia. Faculdade de Filosofia e Ciências Humanas. Departamento de Antropologia. Programa de Pós-Graduação em Antropologia.

Estrada de São Lázaro, s/n,. Cep: 40210-909. Federação Salvador - Bahia - Brasil. urpi@terra.com.br

${ }^{1}$ Este artigo é fruto de uma pesquisa de pós-doutoramento sobre formas de habitar o centro, realizada entre 2016 e 2017, no centro da cidade de Salvador, na área específica da Baixa dos Sapateiros e arredores e, também, no centro de Lisboa. Foram estudados três becos ou avenidas, um pátio e seis casarões ocupados, onde identifiquei formas de habitar em vizinhança, em comunidade, sem vizinhos, com dignidade e coagida. Este artigo irá se referir apenas às duas últimas, encontradas nos casarões. essencial para os trabalhadores precarizados e vulneráveis que habitam, desde o século XIX, o centro da cidade, valor que passa a ser atualmente reivindicado, em discursos e (ou) práticas, como o direito à centralidade.

Minha aproximação das ocupações aconteceu de forma nada programada, quando, em 2016, pesquisava os becos da Baixa dos Sapateiros, antiga rua da cidade de Salvador, tentando encontrar a relação entre uma forma física da habitação - um corredor central com pequenas casas conjugadas a seu redor, os becos - e o tipo de vizinhança que se desenvolvia nela. Entretanto, cada vez que passava pela pequena praça localizada entre a Baixa dos Sapateiros e a Rua das Flores, chamava a minha atenção um casarão envelhecido de cujas janelas superiores e porta de enrolar térrea pendiam roupas coloridas. Embora intrigada, sentia certo receio de bater à porta do que intuía ser uma ocupação. Certo dia, a chuva me fez procurar abrigo no limiar daquele casarão, e foi ali e nesse momento que conheci uma de suas moradoras, uma mulher negra de 
aproximadamente 60 anos, que, naquele preciso momento, pretendia sair. Ela, lamentavelmente hoje falecida, disse-me se tratar de uma ocupação ligada ao Movimento Sem Teto da Bahia (MSTB), cujas lideranças eu devia procurar "para saber mais".

Foi assim que conheci as lideranças que moravam em outro casarão ocupado, dessa vez na Rua do Passo, que concordaram com a pesquisa e me indicaram outras ocupações e os nomes das pessoas que eu devia procurar nelas. ${ }^{2}$ Vale salientar que, em todos os casos, minhas interlocutoras foram mulheres. De fato, "quem quer casa é mulher, quem quer cachorro, periquito, filhos, é mulher". São elas que fazem as ocupações, que vão às reuniões, que lideram cada prédio ocupado.

O trabalho de campo etnográfico em ocupações teve de se adaptar a cada tipo de ocupação. Naquelas onde a presença do tráfico de drogas não é dominante, pude entrar e sair à vontade, procurando observar, participar do cotidiano e conversar frequentemente com as moradoras. Nas outras ocupações, minha entrada ficou restrita a algumas visitas, e as conversações tiveram de ser feitas em outros locais. ${ }^{3}$ As falas das moradoras de ambos os tipos de ocupações são parcialmente reproduzidas em itálico neste texto, sem se mencionar o nome $\stackrel{\sigma}{\sigma}$ de sua enunciadora, por razões de segurança.

ค A primeira seção deste artigo expõe o \& surgimento e a consolidação dos cortiços no CHS. Na segunda, narro a reforma efetuada nesta área - que esvaziou os cortiços em nome

${ }^{2}$ Vale salientar que a concordância com a pesquisa - isto - é, a abertura das portas das ocupações para minhas visitas

$\omega^{\circ}$ e perguntas - exigiu, de forma clara e franca, uma troca

$\infty$ posterior: "Certo, mas vamos precisar de você num segun-

¿ do momento", disse-me uma das lideranças. Foi assim que

i nasceu a disciplina Ação curricular em comunidade e so-

^ ciedade (ACCS, Universidade Federal da Bahia) "O habitar

$>$ em casaróes ocupados de Salvador", cujo resultado devia

ఈิ ser um conjunto de cartografias para o movimento MSTB.

$\nexists 3$ A disciplina ACCS "O habitar em casarões ocupados no त centro de Salvador", que ministro desde o primeiro semestre . de 2018, tornou-se um ótimo espaco para ouvir as moradoI ras dos casarões ocupados. No semestre 2018.1, os encontros

ช aconteceram em salas de um órgão do Estado ou em uma or○ ganização não-governamental (ONG). Esses locais "neutros" garantiram a devida privacidade para que elas pudessem falar à vontade sobre o que significa morar em ocupações com uma presença significativa do tráfico de drogas. do patrimônio, da cultura e dos direitos humanos (Montoya Uriarte, 2003, 2012), que deixou vários casarões vazios, alguns dos quais foram ocupados por sem teto, isto é, por pessoas sem capacidade de pagar o aluguel de uma moradia. A terceira parte expõe a volta dos cortiços em alguns casarões ocupados, agravada por uma situação antes inexistente - o violento tráfico de drogas -, que fez surgir o que chamo de um habitar coagido. A quarta parte discorre sobre uma forma de habitar oposta - o habitar com dignidade -, encontrada na maior parte das ocupações estudadas, pelo menos até o momento. Por fim, fechamos o texto com um elemento comum a ambas as formas de habitar encontradas nas ocupações do CHS: a importância da centralidade que, no discurso ou na prática, é reivindicada como um direito.

\section{SURGIMENTO E CONSOLIDAÇÃO DOS CORTIÇOS NO CHS}

O chamado CHS, mais conhecido como Pelourinho (pilar onde eram supliciados os escravos nessa cidade), é uma poligonal tombada como Patrimônio da Humanidade em 1985. Trata-se de um conjunto arquitetônico colonial, em sua maior parte originado no século XVIII, composto de igrejas, conventos e casarões tipicamente portugueses, chamados sobrados. Os sobrados eram edificações geminadas que seguiam o alinhamento da rua, com dois ou mais pavimentos, retangulares, com testada pequena (5 a 8 metros) e grande profundidade (Gordilho, 2008). Tinham janelas apenas em suas partes frontal e posterior, o que deixava grande parte da área construída dos cortiços escura, abafada e úmida (Freyre, 2004). O aspecto desses sobrados era de opulência, pois morava neles a elite da sede do governo colonial do Brasil, isto é, os grandes comerciantes, desembargadores e senhores de engenho (Mattoso, 1992). No excelente romance histórico Um defeito de cor, escrito por Gonçalves (2009), a personagem principal, uma 
escrava liberta, relembra assim o Pelourinho que ela vira e vivera em meados do século XIX:

Eram grandes os casarões do Pelourinho, todos com muitas janelas e sacadas, onde as famílias se reuniam para assistir aos castigos, como em um teatro. Famílias ricas, de comerciantes ou nobres portugueses, o que acabava dando na mesma coisa, porque, para se ter um título de nobreza, bastava poder comprar. As melhores casas, sobrados de três ou quatro andares, quase grudados uns nos outros, ficavam na parte mais alta do bairro, em um lugar chamado Maciel.

Aquele pedaço de bairro tinha herdado o apelido de um rico senhor que começou a construir o maior solar da região no ano de um mil seiscentos e noventa, e só foi terminar vinte anos depois... (Gonçalves, 2009, p. 216).

A partir do século XIX, os moradores desses sobrados passam a ser outros. A cidade se expande e chegam outros modelos de habitar, trazidos pelos estrangeiros que se instalam na cidade, devido à abertura dos portos e o consequente incremento do comércio. Os proprietários se mudam e alugam suas propriedades antigas no centro da cidade. Inicialmente, alugaram seus sobrados por andares: os pavimentos inferiores a preço menor, para os pobres, e os mais elevados, mais caros, para os mais abastados. O subsolo - uma parte que muitos casarões costumavam ter, aproveitando o desnível do solo, característico da área central da cidade, composta por muitas colinas, algumas bastante íngremes - ficava para os mais pobres, dentre os pobres: os libertos e escravos de ganho (que trabalhavam fora da casa dos donos e lhes pagavam uma quantia fixa diária).

Assim, o subsolo dos casarões foi a primeira modalidade de moradia da população pobre do centro de Salvador (embora, fora da cidade, espalhavam-se outros tipos, como os casebres e os quilombos). Trata-se de uma modalidade que apareceu e cresceu na medida em que avançou o século XIX, quando aumentou o número de escravos libertos e escravos de ganho, que trabalhavam na rua e alugavam espaços para dormir. Numa cidade onde a escravidão tinha impedido até então o apareci- mento de um mercado de habitação popular, os subsolos ou "lojas" tornaram-se a única opção para libertos e escravos de ganho (Costa, 1989, p. 115).

As descrições disponíveis desses espaços foram feitas por médicos higienistas que, impelidos pelas epidemias que assolaram a cidade em meados daquele século, passaram a inspecionar as moradias para detectar os focos de infecção. Essas descrições enfatizavam a grave carência de ar e de luz, bem como a enorme umidade presente neles:

[...] Edificadas muito de encontro às abas das montanhas, tendo até por paredes a rocha ou a terra, e expostas ao occidente, faltam a umas as condições próprias para o arejamento, outras carecem de luz e quase todas reúnem as péssimas condições de excessiva humidade e calor (Comissão de Higiene, 1856, apud David, 1996, p. 26).

Referindo-se a um subsolo, um aluno de medicina fez a seguinte descrição, na década de 1850:

Temos entrado em casas, que mereceriam antes o nome de grutas ou de cavernas, já pela posição subterrânea, já pelo seu aspecto interior. Acompanhai-nos a uma d'estas, atravessemos o seu limiar e veremos o seguinte: seu pavimento húmido e sujo, colocado uma braça, e mais, abaixo do nível da rua, as suas paredes escuras, imundas [...] de maneira que seus habitantes, ahi encerrados e constrangidos, mal podem respirar (Comissão de Higiene, 1856, apud David, 1996, p. 51).

Em finais do século XIX e nas primeiras décadas do século XX, os sobrados das zonas centrais passaram a se subdividir não apenas em pavimentos, mas no interior deles, em pequenos cubículos, mediante tapumes. Tendo sida abolida a escravidão em 1888, sua população não mais era de libertos ou escravos de ganho, mas de operários, carregadores, vendedores ambulantes de comida, pequenos comerciantes, alfaiates, cabeleireiros, sapateiros, quase todos negros e alguns árabes e turcos (Bacelar, 1975). Esses edifícios subdivididos foram chamados, em Salvador, de cortiços; em outras cidades, receberam também o nome de 
casa de cômodos, estalagens ou zungus ${ }^{4}$ (cf. figuras 1-2).

Figura 1 - Moradoras de um casarão subdividido do Maciel, possivelmente na década de 1970

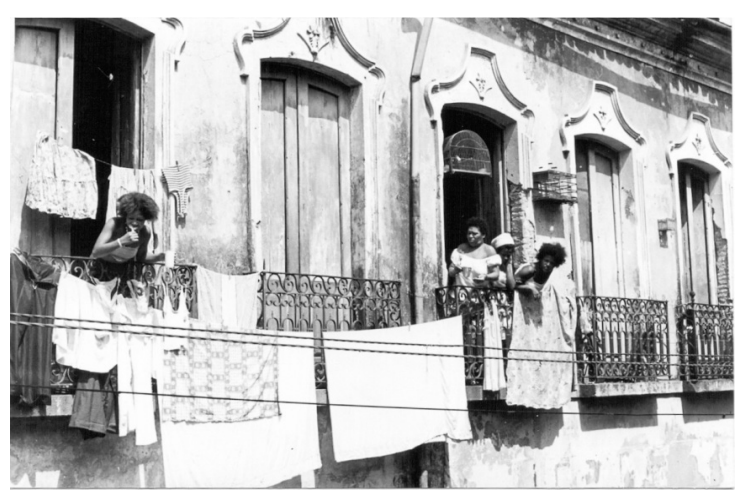

Fonte: Acervo do Instituto do Patrimônio Artístico e Cultural da Bahia, IPAC Museu Tempostal.

Figura 2 - Habitações subdivididas no Maciel, possivelmente na década de 1970

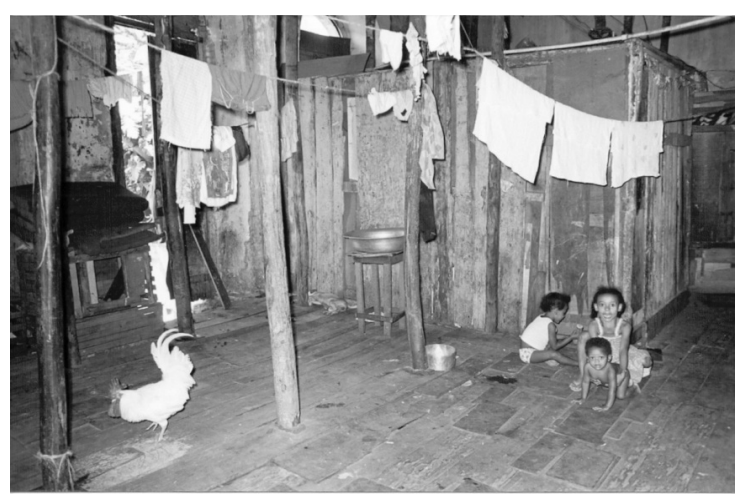

Fonte: Acervo do IPAC, Museu Tempostal.

¿ com três significados: caixa de alvéolos para uma colônia de abelhas; casa com cômodos divididos entre um conjunto de famílias; conjunto de pequenas casas. O significado partilhado nos três sentidos da palavra é a ideia de $\therefore$ pouco espaço para muitos elementos iguais. A $\stackrel{0}{\infty}$ essa ideia somam-se carências consideradas $\dot{\square}$ กे $>$ ventilação e luminosidade. Assim, mais do que ư tipo de habitação com características específicas, a palavra cortiço denotou, nas últimas

" No Rio de Janeiro do século XIX, falava-se em "zungus" para se referir à moradia de homens e mulheres negros. Uma de suas definições era "espécie de casa de cômodos dividida para ser alugada à 'gente da mais baixa, ralé' e lugar de 'imoralidades' para 'vagabundos, capoeiras, desordeiros e ébrios." (Farias et al., 2008, p. 84). décadas do século XIX, uma condição na qual estavam presentes a insalubridade, a densidade, a promiscuidade, a pobreza e a estreiteza.

Em Salvador, a palavra cortiço, já no século XX, foi usada basicamente para designar os "palacetes deserdados de seu papel histórico" (Santos, 1959, p. 182), isto é, os casarões subdivididos:

Perdendo essas moradias sua feição afidalgada, aí a densidade de moradores era maior ainda; lá, onde tinham vivido poucos indivíduos, concentraram-se dezenas de famílias que foram ocupando todos os espaços disponíveis: quartos que se subdividiam por paredes frágeis em inúmeros outros, becos formados debaixo das escadas, edículas que foram sendo construídas nos quintais, nos porões e sótãos, nos desvãos dos telhados ou dos pisos (Wissenbach, 1998, p. 103).

Em Suor, romance escrito na década de 1920 e publicado na década seguinte, Jorge Amado descreveu um cortiço do Pelourinho da seguinte maneira:

Parecia um velho sobrado como os outros, apertado na ladeira do Pelourinho, colonial, ostentando azulejos raros. Porém era imenso. Quatro andares, um sótão, um cortiço nos fundos, a venda do Fernandes na frente, e atrás do cortiço uma padaria árabe clandestina, cento e dezesseis quartos, mais de seiscentas pessoas. Um mundo. Um mundo fétido, sem higiene e sem moral, com ratos, palavrões e gente. Operários, soldados, árabes de fala arrevesada, mascates, ladrões, prostitutas, costureiras, carregadores, gente de todas as cores, de todos os lugares, com todos os trajes, enchiam o sobrado. Bebiam cachaça na venda do Fernandes e cuspiam na escada, onde, por vezes, mijavam. Os únicos inquilinos gratuitos eram os ratos. Uma preta velha vendia acarajé e mungunzá na porta (Amado, 2011, p. 10).

Em meados do século XX, eram muitos os cortiços no CHS que, devido à expansão comercial que expulsava moradores de prédios até então de uso residencial, foram se adensando cada vez mais. Assim, embora a população residente no centro diminuísse de 7,9\% em 1940 para 4,8\% em 1950 (Santos, 1959, p. 131), os que ficavam passavam a morar em um número menor de ruas que se especializaram 
como zonas de cortiços. Eram as ruas Ângelo Ferraz, Santa Isabel, Inácio Accioly, Padre Nóbrega, São Francisco, Muniz Barreto etc., todas no Pelourinho. Essa área se tornou um grande cortiço: no Maciel (uma micro área do CHS), em finais da década de 1960, havia "223 imóveis, dos quais 132 são casas-de-cômodos e 27 são unidades residenciais de grupos familiares, enquanto que os demais se distribuem em: comerciais (com exclusividade), ruínas, em conserto e fechados" (Espinheira, 1971, p. 15). O adensamento e os estragos do tempo nas edificações antigas tornavam as condições de moradia cada vez mais precárias ${ }^{5}$ (Cf. Figuras $3,4,5$ e 6$)$.

Figuras 3 e 4 - Prédios reformados e não reformados no Maciel, possivelmente na década de 1970
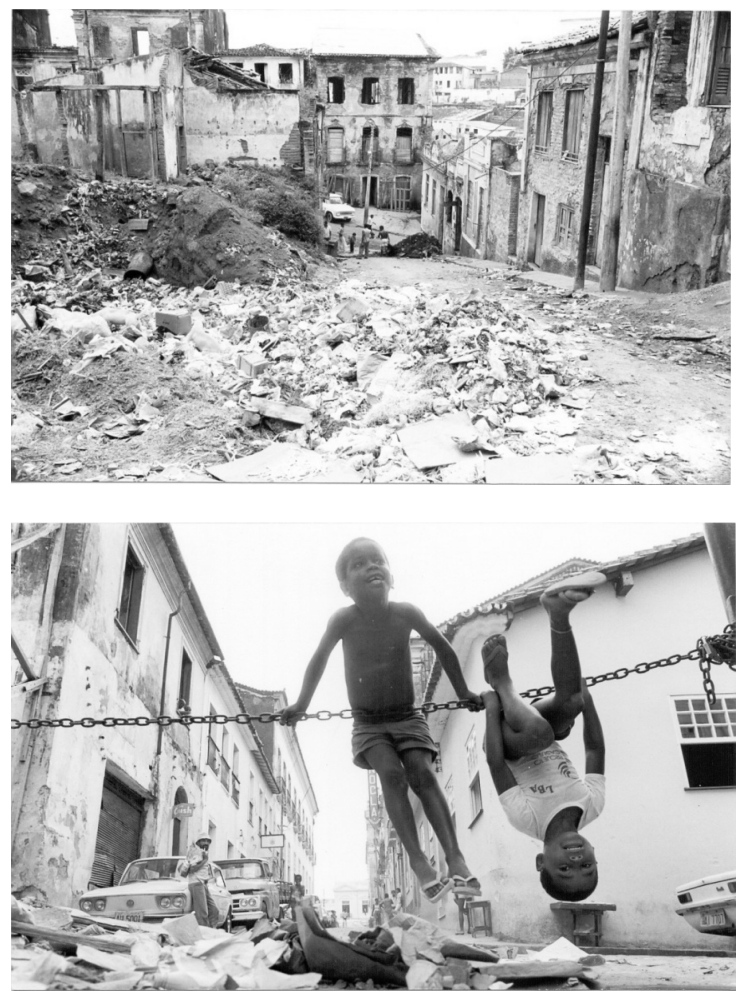

Fonte: Acervo do IPAC, Museu Tempostal.

${ }^{5} \mathrm{O}$ aumento substancial do número de prédios ruindo é um bom indicador dos efeitos do tempo e do descaso de seus proprietários e do Estado, supostamente encarregado de salvaguardar ou fiscalizar o patrimônio. Em 1969, eram 13 os prédios totalmente arruinados no Maciel; em 1978 já eram 41 e, em 1988, eram 51 prédios. Em 1991, 30 prédios desabavam por ano.
Figuras 5 e 6 - Ruínas e escombros no Maciel. Beco do Mijo (Rua Inácio Accioly), possivelmente na década de 1970
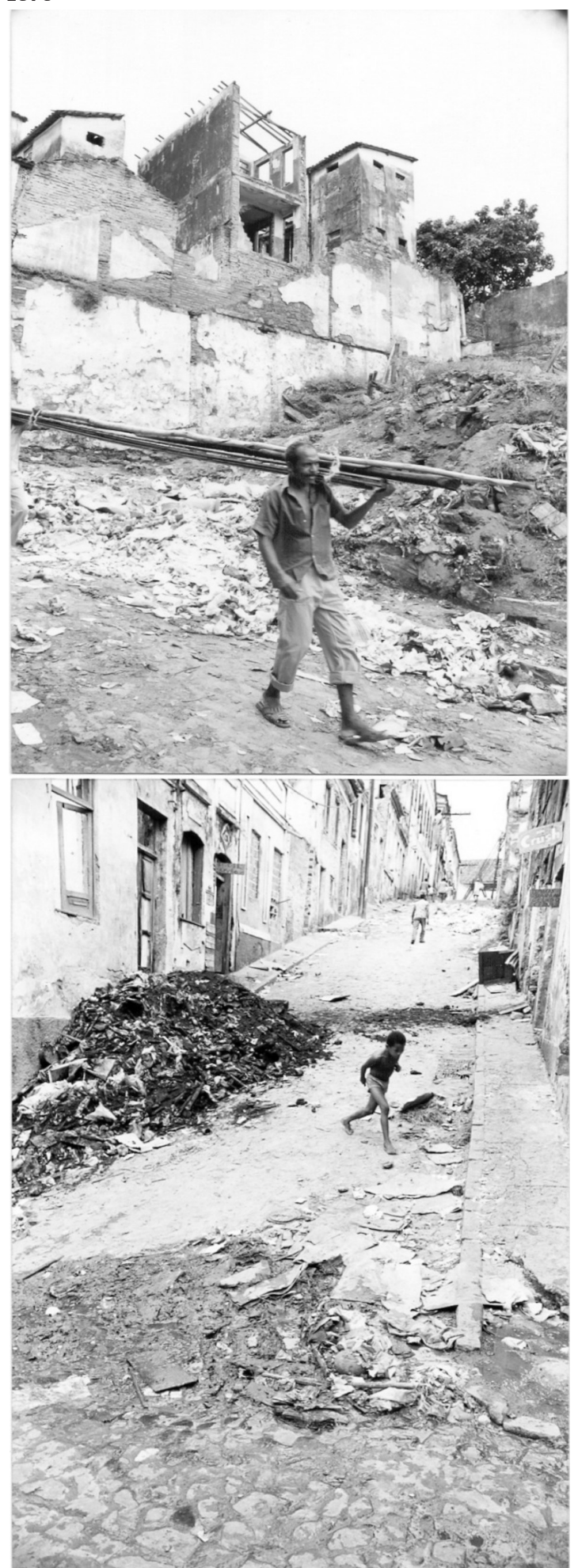

Fonte: Acervo do IPAC, Museu Tempostal.

Na década de 1950, Milton Santos assim descreveu o palacete número 24 da Rua Ribei- 
ro dos Santos, chamado Casa das Sete Mortes, onde o primeiro pavimento foi dividido em 18 peças, 11 das quais eram dormitórios nos quais moravam 40 pessoas:

[...] Salas e quartos demasiadamente pequenos, verdadeiras células, estão separados por paredes de madeira. Nesses cubículos não há luz, nem ar e inexiste higiene. A vida nesses cortiços é um verdadeiro inferno e as diversas famílias que ocupam um mesmo andar se veem obrigadas a se servirem de um único banheiro e uma só latrina. Escadas estragadas, soalhos furados, paredes sujas, tetos com goteiras formam um quadro comum a toda essa zona de degradação (Santos, 1959, p. 166).

$\mathrm{O}$ "mundo fétido, sem higiene e sem moral”, nas palavras de Jorge Amado na década de 1920, tornou-se "um verdadeiro inferno" nas palavras de Milton Santos na década de 1950. Na década de 1970, a densidade populacional dos cortiços fez com que o tamanho médio dos quartos fosse de $4 \mathrm{~m}^{2}$. Um sobrado de 2 pavimentos, com 2 quartos, costumava ser adaptado por tapumes para abrigar 24 quartos. Nos corredores, moravam os mais pobres dentre os pobres. Bacelar (1982) fez a seguinte descrição interna dos cômodos:

Os cômodos do Maciel têm, em média, 3 a 5 m2; são, em sua maioria, ocupados por uma cama, e, quando o grupo tem mais de um filho, é feita a adaptação de algum móvel ou estrado de madeira para que possam dormir; tem ainda um guarda-roupa ou uma penteadeira onde arrumam o vestuário e acessórios. Muitas vezes estes equipamentos são substituídos por uma mesa, onde são colocados os acessórios de beleza, e o vestuário é arrumado em cabides ou pregos na parede. Têm um pequeno fogão "jacaré" e o mínimo equipamento de cozinha: uma ou duas panelas, o mínimo indispensável de pratos, colheres, garfos e facas. [...] A iluminação e aeração do quarto é a mais precária possível, em especial quando a porta é fechada. Não possui janelas, excetuando-se quando se situa de frente, de fachada, nos pavimentos superiores. Possui sempre imagens ou retratos dos santos protetores, além de fotografias dos ídolos da TV coladas nas paredes (Bacelar, 1982, p. 96).

Apesar das condições descritas, o preço dos aluguéis em cortiços era, em termos relativos, absurdamente alto, fato que pode ser explicado pela enorme demanda por moradia popular no centro (Cardoso, 1991, p. 67) e, no caso dos grupos discriminados, dentre os quais os travestis, pela quase nula possibilidade de conseguir habitação em outras partes da cidade (Kulick, 2008).

Ao longo do século XX, a população dos cortiços não variou significativamente. Como vimos, Jorge Amado escreveu tratar-se de "operários, soldados, árabes de fala arrevesada, mascates, ladrões, prostitutas, costureiras, carregadores"; para as primeiras décadas, Bacelar (1975) se referiu a operários, carregadores, vendedores ambulantes de comida, pequenos comerciantes, alfaiates, cabeleireiros, sapateiros, árabes e turcos; Milton Santos relatou serem "pequenos empregados ou pessoas sem uma ocupação permanente ou bem definida. Seu local de trabalho era, de preferência, no centro da cidade" (Santos, 1959, p. 167). Segundo estudo coordenado por Vivaldo da Costa Lima na década de 1960, os homens trabalhavam como engraxates, biscateiros, mecânicos, pintores, pedreiros, serventes (Secretaria de Educação e Cultura do Estado da Bahia, 1969); dentre as mulheres, o meretrício tornou-se atividade principal: em 1967, as prostitutas do Pelourinho eram $42,0 \%$ das moradoras da área. Na década de 1980, uma pesquisa demonstrava a permanência do perfil de seus moradores: a maioria dos residentes eram vendedores, domésticos e prostitutas, e 50\% deles não chegava a ganhar 2 salários mínimos (Simões; Moura, 1986).

\section{A REFORMA DO CHS, OS CASA- RÕES VAZIOS E SUA OCUPAÇÃO POR SEM TETO}

Entre os anos de 1993 e 1999, deu-se início a uma reforma radical do CHS, concebida pelo IPAC, realizada pela Companhia de Desenvolvimento Urbano do Estado da Bahia (CONDER), com recursos do governo do Estado. Foi "recuperado" o patrimônio material de uma grande parte da poligonal tombada como patrimônio da humanidade. ${ }^{6}$ Quarteirões inteiros foram ${ }^{6}$ Resta ainda toda uma área chamada de $7^{\mathrm{a}}$ etapa cuja re- 
esvaziados de sua população pobre e negra para serem reformados e transformados, posteriormente, em lojas, restaurantes, museus e ateliês, isto é, criou-se uma área de turismo, lazer e cultura na qual a função residencial foi banida. Apenas 3,1\% dos imóveis do Pelourinho "recuperado" manteve essa função (Governo.., 1997-1998), o que significa que $95 \%$ dos moradores que ali residiam foram expulsos (Montoya Uriarte, 2003, p. 79). Segundo números oficiais, até o final da década de 1990, 85\% dos moradores foram indenizados para saírem do CHS. De fato, foram 3.190 pessoas (Gottschall; Santana; Rocha, 2006, p. 35) expulsas, pois elas não "saíram", nem foram "retiradas", ou apenas "removidas". Foram expulsas não só pelas indenizações irrisórias, mas porque queriam ficar e não foi lhes dada essa possibilidade. Na década de 2000, foram expulsos outros tantos, correspondentes aos moradores do que se chamou de $7^{\mathrm{a}}$ etapa e da área da Rocinha. Só podemos especular o número total até hoje, um número que deve certamente ultrapassar 6.000 pessoas.

Os antigos cortiços foram todos esvaziados. Mas a população expulsa voltou, retomou o território de diversas formas: como vendedores ambulantes de produtos diversos para os turistas, como pedintes nas ruas reformadas onde antes moravam, como usuários de drogas nas ruas ainda não reformadas ou como inquilinos das margens da área reformada. O fato é que a pobreza que foi expulsa do Pelourinho não abandonou a área. Nos anos 2000, um estudo verificava que

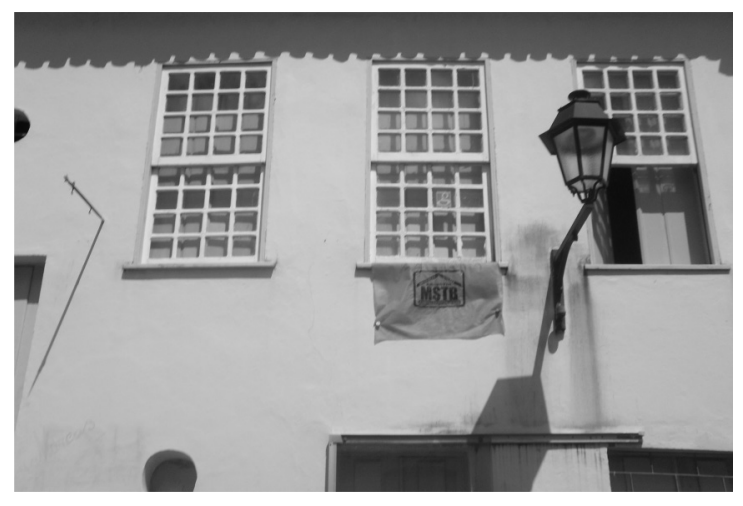

forma se alastra desde os anos 2000 até agora. Nessa área, uma margem do Pelourinho "recuperado", sobreviveram cortiços convivendo com ruínas.
[...] no entorno principal, sobretudo nas áreas não reformadas, reside uma população extremamente pobre que sobrevive em casarões degradados, tem baixa escolaridade e parco rendimento [...]. Todos os indicadores sociais do Censo 2000 indicam as sub-regiões Pelourinho-Sé e Misericórdia-Castro Alves como sendo as mais vulneráveis, onde as condições de precariedade aparecem de forma mais acentuada (Gottschall; Santana; Rocha, 2006, p. 23-24).

Retomaram o centro, também, como "Sem Teto", ocupando casarões reformados do CHS e da maior área antiga denominada Centro Antigo de Salvador (CAS), dando uso a parte dos 1.400 imóveis vazios, subutilizados, em ruínas e (ou) fechados do CAS (Pires; Souza, 2014, p. 168). "Porque nós não temos onde morar havendo tantos imóveis vazios?”, perguntam-se com razão as moradoras dos prédios ocupados do CHS com as quais trabalhamos (Cf. Figuras 7-12) ${ }^{7}$.

Figuras 7-12 - Casarões e prédios ocupados por Sem Teto no CHS, cuja população acompanhamos e ouvimos ao longo do trabalho de campo

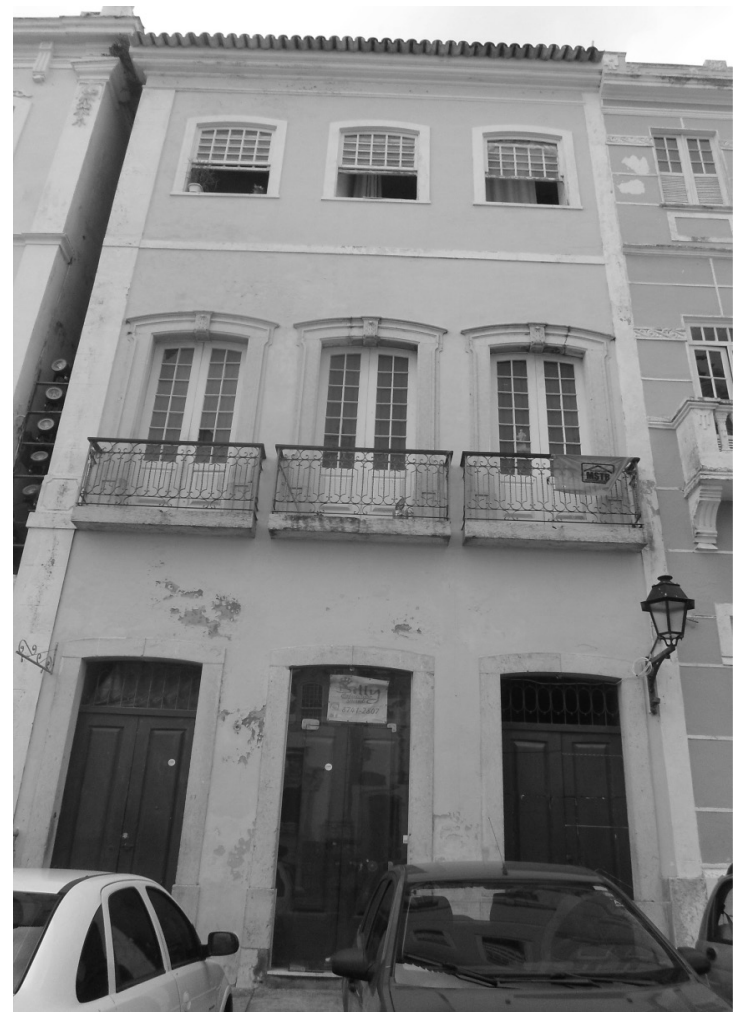

7 Na Região Metropolitana de Salvador, o número de domicílios vagos é enorme. Conforme se lê no Atlas sobre o direito de morar em Salvador (Santos et al., 2012, p. 71), "enquanto o déficit habitacional urbano é de 114.524, o número de domicílios vagos é de 140.890, o que significa que temos imóveis suficientes para acabar com o déficit habitacional". 

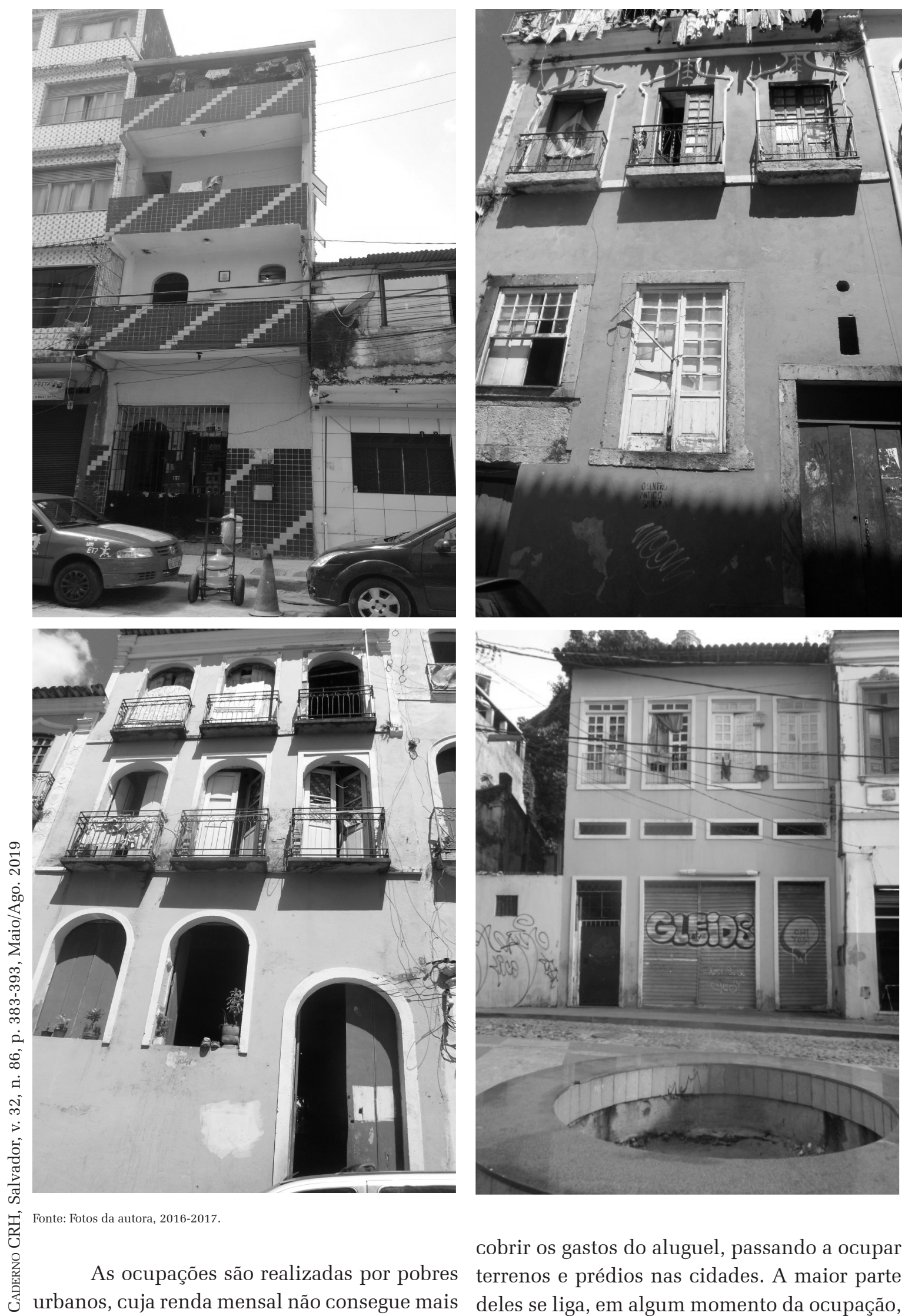

cobrir os gastos do aluguel, passando a ocupar terrenos e prédios nas cidades. A maior parte deles se liga, em algum momento da ocupação, 
a um dentre os vários movimentos Sem Teto que surgiram a partir de finais da década de $1990 \mathrm{em}$ todas as grandes cidades brasileiras. Em 2010, existiam, em Salvador, 36 ocupações de Movimentos Sem Teto, envolvendo 5.027 famílias, totalizando 21.415 pessoas (Santos et al., 2012). ${ }^{8}$ A metade dessas ocupações era de terrenos e $39,0 \%$ de prédios, 3/4 partes delas estavam localizadas na Cidade Baixa, em direção ao Subúrbio Ferroviário, 16,2\% nos bairros do centro, centro histórico e Nazaré e 8,1\% no Miolo (idem, p. 25-26).

Em contraste com a ocupação de terrenos na periferia das cidades, onde a população pobre autoconstruiu suas casas, principalmente no período entre 1950 e 1980, as ocupações dos Sem Teto (seja de terrenos, seja de prédios) não visam à autoconstrução, mas à pressão sobre o poder público para que tome as medidas necessárias ao enfrentamento do gravíssimo problema de déficit habitacional dos setores mais pobres da sociedade. Em Salvador, segundo a Prefeitura Municipal de Salvador, esse déficit atinge 90.000 famílias; segundo o Instituto Brasileiro de Geografia e Estatística (IBGE), 118.000 famílias e, segundo o Movimento Sem Teto da Bahia, 150.000 famílias (Miranda, 2008, p. 68).

Os casarões ocupados apresentam características bastante diversas no que diz respeito: ao tempo de ocupação do imóvel (alguns 10 anos; outros, 1 ano); ao número de pessoas que ali moram (100 pessoas em alguns e 10 pessoas em outros); ao tamanho do imóvel (de muitos, ou apenas dois pavimentos); e à existência ou não de uma liderança forte e regras efetivas de convívio. Outra diferença muito importante é a presença ou não do tráfico de drogas em seu interior.

Apesar dessas distinções, todas as ocupações partilham uma situação estrutural de

${ }^{8}$ Em São Paulo, dada a magnitude dessa cidade, os números são maiores. Entre o início de 2013 e o fim de 2014 , segundo a Polícia Militar local, 681 prédios ou terrenos ociosos tinham sido ocupados. Em 2015, eram 4.000 as pessoas morando em cinemas, hotéis, antigos edifícios comerciais e casarões ocupados no centro da capital paulista (Senra, 2015). indeterminação permanente, que advém da possibilidade de, a qualquer momento, seus moradores serem despejados por mandato judicial de reintegração de posse. As ocupações sofrem, dessa maneira, uma insegurança constante, que impossibilita qualquer projeto a médio prazo ou a longo prazo, o que traz como consequência a precariedade que se torna incessante e a sensação de indeterminação persistente (que renasce a cada boato, a cada pequena mudança conjuntural, a cada resultado eleitoral ou troca de interlocutores institucionais). As ocupações vivem, assim, sob o paradoxo do provisório-permanente, o que impele melhorias contingenciais, apropriações parciais, enraizamentos passageiros, soluções caracterizadas pelo efêmero, temporário, improvisado. Vive-se anos a fio na precariedade, mediante táticas, arremedos, cacarecos, "gambiarras" ou "armengues", vocabulário local que nomeia o que Certeau (1994, p. 74) conceituou como "bricolagem" ou "trampolinagem”, que são as artes de fazer daqueles que dominam o tempo, mas não o espaço. Apesar dessa situação estrutural, habitam-se as ocupações, isto é, criam-se relações entre seus habitantes e entre eles, o ambiente e objetos que o constituem. Mas o fato de habitar as ocupações não torna o morar nelas algo menos angustiante:

"Eu quero ter minha casa, a vida na ocupação é difícil, sempre deixa a desejar, começa com alegria e termina com tristeza, é muita ilusão, é muito doloroso" (entrevistada).

Ao receio de ser desalojado, soma-se o medo das incursões policiais e seus modos violentos de tratar a população que mora em ocupações. Com medo, estresse e angústia acumulados durante anos, uma moradora nos disse precisar tomar antidepressivos, os quais para de ingerir quando chove, pelo pavor de não acordar e o prédio desabar sobre ela e sua família. 


\section{O HABITAR COAGIDO: o agrava- mento dos velhos cortiços}

Neste momento, torna-se necessário fazer uma breve conceituação do que chamo de habitar. Com Heidegger (1954) e Ingold (2002), entendo esse conceito de uma forma bastante ampla. Habitar é a forma humana de ser no mundo: é integrar elementos, relacionar coisas, reunir componentes. Considerando que o ser é um ser-no-mundo, ou seja, um ser em relação intrínseca com o mundo, um ser centrífugo que precisa se estender, lançar raízes para fora de si, habitar é esse enraizamento com as coisas e seres de um espaço. É esse estar-junto, em-meio-a, conectado-com, entrelaçado-a, envolvido-com, junto-a, enredado-em. Habitamos na medida em que estabelecemos relações com o meio e os seres que nele vivem, relações que são constituídas no dia a dia. Mas não se pense que habitamos apenas casas. Habitamos diversos lugares. Os percursos entre eles, especialmente os que são efetuados a pé, formam áreas densas em histórias e memórias, como no Centro, por exemplo, que nos ajudam a entender o apego que suscitam em seus moradores.

Dentre os seis casarões ocupados, encontrei, em dois deles, as mesmas características físicas dos antigos cortiços: umidade, escuridão, F serviços de água e higiene coletivos, quartos diminutos separados por tapumes, excesso de gente. Os ambientes exíguos e muito próximos, com divisórias que não chegam até o teto devido ao pé direito alto das construções antigas, promove a mesma desconfiança e retraimento que Kovarick (2009, p. 272) detectou nos corti$\therefore$ ços por ele estudados no centro de São Paulo. \& Trata-se de um habitar apertado, um estar-junc to extremo, ocasionando o que o sociólogo cha$\therefore$ mou de "sociabilidade do distanciamento".

Há, no entanto, um elemento novo que agrava esse velho habitar. Trata-se do tráfico de drogas, que promove um estar-junto coagido e transforma o distanciamento para com os vizinhos num habitar contra os vizinhos. As relações se reduzem, a ponto de criar um ambiente tenso, de desavenças, de incomodidades acumuladas, frutos da lei que rege neles: a lei do silêncio, ou de "ficar na sua", "fingir que não vê", "fazer vista grossa", não delatar, não se intrometer, não comentar, fazer de conta que não vê e nada fazer contra as atividades do tráfico, sob pena de sofrer violentas consequências. "Entraram para a vida do crime, tomaram conta, ninguém pode falar muita coisa". Essa situação impera nos prédios ocupados, mas também, é preciso frisar, em áreas ou bairros populares inteiros tomados pelo tráfico. Assim, os traficantes se tornam os donos do lugar, os donos da rua ou os donos do prédio. Conviver sob esta lei, nos prédios ocupados, torna o habitar desconfiado e temeroso, aumentando ainda mais o retraimento ou distanciamento entre vizinhos, que advém do excesso de proximidade. O resultado é a vontade de encontrar outro lugar para morar:

\begin{abstract}
"Vou falar a verdade, se tivesse outro lugar pra ir, eu ia, só não saio do centro porque trabalho aqui, estaciono [guardo] carros na porta da faculdade no Comércio, é só descer o Taboão e estou lá, sem contar com a escola dos meus filhos, fico tranquila porque eles passam o dia todo lá e é perto de casa”.
\end{abstract}

Uma moradora também expressou seu desejo de sair, mesmo que seja para um "bairro". Entretanto, foi consciente de que até essa alternativa era, de fato, inexistente: "Aqui a gente não pode sair para bairro nenhum, não pode ir para a Liberdade porque [somos] do Pelourinho". Sua narrativa explicita o conflito entre as diversas facções do tráfico que se alastram entre territórios, nos quais cada bairro possui a identidade com uma facção.

Os traficantes costumam entrar devagar, primeiro num quarto. Muitos são generosos: "Bandido se aproveita da pobreza. Paga um feijão, paga um gás. Compra o apoio da pessoa, seu silêncio ou sua conivência. Eles dão dinheiro e, com isso, te calam”. Depois, vão ocupando mais quartos, tornando-os locais de venda de drogas, ou "boca de fumo". A venda torna necessário que todo o espaço passe a ser controlado pelo "gerente do movimento" (Birman; 
Fernandes; Pierobon, et al., 2014), que controla quem entra e quem sai e a que horas, proibindo visitas que possam "dedurar", fazendo festas onde todos os excessos se permitem. Os controles são feitos mediante a violência, e o convívio passa a ser marcado por ameaças de morte e xingamentos, às vezes com armas nas mãos. Quando a liderança decide enfrentar o tráfico, ela sofre represálias duríssimas. Uma delas nos deu seu depoimento: disse ter sido ameaçada de morte e teve sua casa incendiada, sobrevivendo apenas porque não estava no prédio ocupado no momento. Sobreviveu, mas perdeu todos os seus pertences. Além de perder a esperança e a força para lutar: "A gente vai perdendo força, estamos desistindo do movimento".

Os casarões ocupados que apresentam esse habitar apertado e coagido são ocupações que partilham algumas características importantes. Em primeiro lugar, eles têm vários anos de existência e foram feitos sem uma seleção coletiva apurada de seus moradores. Cada um dos agentes que ocupava ia chamando conhecidos para realizá-la, sem haver uma aprovação dos futuros moradores, nem um conhecimento mútuo entre todos eles. Nas lideranças, há consenso sobre as consequências desse início: "O problema maior é a forma como se ocupa e isso deixa o tráfico tomar conta. Não há uma seleção apurada das pessoas, uma organização prévia sólida”.

Por outro lado, além da entrada de pessoas desconhecidas, sua rotatividade é grande: muitos ficam pouco tempo e deixam seus próprios conhecidos no lugar. O resultado é um desconhecimento generalizado, o que torna mais difícil a convivência.

Em segundo lugar, são ocupações que apresentam um nível baixo de organização. Ela é difícil de advir devido ao desconhecimento entre as pessoas e à sobrelotação, o que cria um clima pouco favorável para encontrar consensos e criar regras de convívio. Sem regras, os espaços coletivos - quintais, corredores, escadas - ficam descuidados, parecendo "zo- nas de ninguém". Sendo a organização fraca, a autoridade do coordenador do prédio se torna igualmente frágil. O resultado é um vazio de autoridade que permite que “...a bandidagem tome conta porque as pessoas deixam de tomar conta. Falta coragem, autoridade”.

Os líderes do movimento são também ameaçados: "O movimento não faz nada contra a marginalidade. O movimento já foi ameaçado de morte".

Em terceiro lugar, são ocupações cujos moradores se encontram entre os mais pobres dentre os pobres. A luta pela sobrevivência é feita a cada dia, a cada refeição: "Toda manhã é um dia de sobrevivência, de trabalho para colocar comida na mesa. Como arrumar o local onde se mora nessas condições?" Com efeito, quando a necessidade de trazer comida para dentro de casa é um desafio a ser enfrentado diariamente, a cada refeição, qualquer outro objetivo, nessas condições, é visto como supérfluo ou desnecessário.

Embora, em muitos casos, haja, entre os moradores, uma oposição moral que condena os traficantes ou bandidos por não seguirem a "ética do trabalho" (Zaluar, 1985), surpreendentemente, em muitos outros, essa atividade é compreendida e até justificada. O fato é que a pobreza e a fome ajudam a naturalizar o tráfico de drogas. Para muitos moradores de prédios cujo habitar é alvo de coação do tráfico, a ausência de trabalho, a má remuneração e a necessidade de sobreviver ou alimentar uma família tornam as drogas um caminho plausível e até compreensível: "As drogas são uma forma de sobrevivência. Estão em toda parte".

\section{HABITAR COM DIGNIDADE: uma experiência rica de autogestão e liderança feminina}

Em quatro das seis ocupações pesquisadas, os moradores avaliam seu habitar como "morar com dignidade". Essa expressão nativa reúne a sensação de bem-estar promovida pela 
suficiência de espaço, a privacidade das unidades familiares, o cuidado com o espaço coletivo e a boa relação com os vizinhos. Esse habitar se caracteriza, assim, em primeiro lugar, pelas regras e a importância conferida ao espaço: “ $O$ tamanho das casas deve ser digno de moradia, não pode ser buraco, cubículo"; "Aqui é tudo organizado, claro, limpo. Bandidagem não entra. Eles gostam do escuro".

Em uma dessas ocupações, as regras são as seguintes: "Moradia digna, nada de cubículo; tráfico não entra; quem quiser fumar baseado (cigarro de cannabis) o faça dentro de sua casa (não pode no quintal); não se pode incomodar os vizinhos com volume alto; nada de gritaria". E a importância do espaço é assim frisada:

A ocupação que fizemos aqui foi por apartamento. [...] Aqui tem 6 apartamentos e tem seis famílias. Nós queremos morar com dignidade. As pessoas, quando não têm casa, no desespero, saem dividindo os espaços com papelão. Eles não têm noção do que é morar com dignidade, o que é ocupar com dignidade para, inclusive, ter o respeito do próprio governo. Além disso, quando a ocupação não se dá ao respeito, fica fácil até mesmo para a área ser ocupada pelo tráfico de drogas. Eu nunca quis ocupar para dividir a minha casa em dez. Eu trabalho, eu voto e eu quero morar bem (Santos et al., 2012, p. 96).

Em segundo lugar, no habitar com dig$\stackrel{\circ}{\circ}$ nidade, a relação com os vizinhos é consideSิ rada boa, na medida em que os limites entre o $\therefore$ coletivo e o privado estejam bem delimitados e defendidos. Os vizinhos se falam nos corredores, nas portas, ou até de uma janela a outra, mas as portas das casas se mantêm fechadas, e a música de um não é a música de todos; be$\dot{2}$ bem juntos, vez por outra, em algum local, e se $\lesssim$ encontram em reuniões do movimento ou do i. prédio, mas há um respeito pelo espaço individual e pela individualidade de cada unidade familiar. Assim, não há banheiros comuns ou cozinhas comunitárias - "isso é coisa de paulista!" - nem espaços coletivos ou confraternizações envolvendo todos.

Em terceiro lugar, o habitar com dignidade supõe um cuidado estético especial com o espaço coletivo (e o individual também). Os que ocupam esse tipo de prédio procuram manter, na medida em que seu parco ingresso lhes permite, as áreas coletivas iluminadas, pintadas, decoradas, limpas e protegidas (com cadeado, especialmente à noite). Misturam-se restos de pintura, reciclam-se objetos, tampam-se buracos com o que for: o que importa é o cuidado com a infraestrutura. O apartamento também precisa ser limpo, pintado, iluminado, decorado, consertado. Apesar de todas as dificuldades econômicas, muitas vezes com doações ou sobreposição de estilos, a estética se impõe. As comodidades são igualmente importantes: os eletrodomésticos não são vistos como luxo, mas como parte do habitar com dignidade que todo trabalhador merece para si.

\begin{abstract}
Somos Sem Teto, não somos mendigos. Nós temos duas pernas e dois braços. Lugar de mendigo é no albergue. ...... sai com a carrocinha dela e vende o queimado, a outra é garçonete, outra é cozinheira, outro trabalha na portaria. Quem fica na portaria recebe. Não tem aquele “dinheiro”... Mas dá pra viver... Uma vez, um policial invadiu aqui e disse: “Sem Teto com televisão, DVD?” Eu disse: “Nós somos Sem Teto, não somos mendigos não! Nós trabalhamos". Com o dinheiro do aluguel, da luz e da água, a gente compra o que precisa à prestação, em 12 vezes, compra geladeira de segunda mão. Se fosse para pagar aluguel, a gente não tinha nada não. Iria ser despejado como eu fui. Aqui não tem vagabundo (Santos et al., 2012, p. 105-106).
\end{abstract}

As ocupações que conseguiram construir um habitar com dignidade têm em comum a enorme importância das mulheres. Em todos os casos, são ocupações coordenadas por mulheres com um perfil muito singular: mulheres de personalidade forte, autoridade e determinação, com uma garra e uma presença que podem até amedrontar, que fazem e dizem que fazem: " $A$ gente não pode discriminar, tem que incluir. Mas aqui [no prédio] eu faço uma seleçãozinha. Não quero aglomeração de bandidagem”.

Em todos os casos, também se trata de casarões onde a grande maioria dos moradores são mulheres. Trata-se, ainda, de mulheres aparentadas por laços de sangue ou amizade 
de longa data. Foram elas as que planejaram as ocupações e as que selecionaram seus futuros moradores com o critério do gênero, preferindo as unidades familiares chefiadas por mulheres, amigas ou parentes. Assim, o parentesco na linha feminina, elemento tão importante encontrado no habitar dos becos ou avenidas pesquisadas na Baixa dos Sapateiros e que propicia um habitar com vizinhos (Montoya Uriarte, 2019), aparece novamente nas ocupações como elemento aglutinador do habitar.

\section{À GUISA DE CONCLUSÃO: o direi- to à centralidade}

Velhos casarões do Pelourinho - agora reformados e pintados - voltaram a abrigar o mesmo perfil dos moradores do centro de Salvador de um século atrás: autônomos, informais, ambulantes, desempregados, subempregados, sobreviventes das tarefas que o centro da cidade permite (limpadores de carros, catadores de materiais recicláveis, carregadores, vendedores de rua, pedintes etc.). Inclui-se agora, é verdade, em algumas ocupações, uma profissão nova que cresce em todos os bairros populares: os traficantes. Mas as formas de habitar esses casarões mudaram: naqueles onde o habitar apertado permaneceu, acrescentou-se o habitar coagido; em outros, inventou-se, com muito esforço, uma forma de habitar com dignidade, uma experiência que não pode deixar de ser louvada e, principalmente, não pode ser ignorada por aqueles que planejam ou pensam as políticas habitacionais.

Para além do prédio ocupado, todos habitam o centro da cidade. E é nele que querem ficar, apesar de todos os problemas e todas as tentativas, antigas e recentes, de expulsá-los. Para eles "o centro é tudo": tudo perto, tudo mais fácil, tudo possível. Desde os tempos das "lojas" ou subsolos partilhados por libertos e escravos de ganho, até os dias de hoje, a centralidade é um valor essencial para aqueles que habitam o centro.
Dentre todos os fatores que a centralidade promove, o trabalho é aquele que mais aparece destacado, pela sua inegável importância para a sobrevivência. "É preciso morar em um local no qual a gente possa sair para trabalhar. De que adianta morar em uma casa bonita e ficar com fome, de braço cruzado, sem poder trabalhar? Tem muita gente na rua que recebeu a casa em bairro distante, mas não tem como sobreviver", disse o morador de um prédio ocupado à equipe que redigiu o livro Atlas sobre o direito de morar em Salvador (Santos et al., 2012, p. 86). Com efeito, a centralidade é sobrevivência, mas também, e não menos importante, é rede de relacionamentos e memória alimentada nos percursos diários, trajetos cotidianos e circuitos traçados ao longo de anos de moradia em diversas casas do centro da cidade.

Em contraste com o passado longínquo e recente, a centralidade hoje não é somente praticada: ela é parte de um discurso que, a meu ver, a considera como um direito. Os movimentos Sem Teto afirmam claramente: "Não queremos remanejamento. Queremos centro histórico. A história da gente está aqui". Tal como os moradores organizados da $7^{\mathrm{a}}$ etapa da Reforma do Pelourinho afirmavam em inícios da década de 2000: "Você acha que eu, com este tanto de filhos, vou pra Coutos? Vou aceitar esse dinheiro que a CONDER está dando? Só saio do Centro Histórico para outro lugar no Centro Histórico! Se não me derem outra casa por aqui, só saio dentro de um caixão." (Bittencourt, 2015, p. 86).

A articulação de movimentos - Artífices da Ladeira da Conceição da Praia, Associação Amigos de Gegê dos Moradores da Gamboa de Baixo, Movimento Sem Teto da Bahia (MSTB), Movimento Nosso Bairro é 2 de Julho, Coletivo da Vila Coração de Maria, Comunidade da Ladeira Preguiça, Associação de Moradores e Amigos do Centro Histórico (AMACH) e Associação de Moradores da Chácara Santo Antônio - produziu recentemente um pequeno texto para o ato-cortejo do 2 de julho de 2017 , 
intitulado "O centro antigo é do povo", que vale a pena reproduzir:

Nós participamos da história do Centro Antigo desde sua construção, em cada pedra, de cada rua e cada casa. Erguemos com nosso suor, nosso trabalho, nossa cultura e criatividade. Hoje, depois de quase cinco séculos, continuamos resistindo e vivendo para mantê-lo vivo e de pé. Somos nós que moramos nos casarões abandonados por proprietários irresponsáveis e sem compromisso com o Centro e com sua história.

Mais uma vez querem nos expulsar das nossas casas, para dar lugar a um modelo de turismo que não nos inclui e a uma classe que não nos aceita. Nós não aceitamos sair do nosso lugar, nem o apagamento das nossas memórias.

Não vamos aceitar ver o povo negro expulso de novo.

O Centro Antigo está cheio de vida e essa vida somos nós, nossos corpos, nosso trabalho, nossos passos, nosso viver!

O CENTRO ANTIGO EXISTE!

O CENTRO ANTIGO RESISTE!

O CENTRO ANTIGO É DO POVO! ${ }^{9}$

Por outro lado, há aqueles, que, sem organização coletiva e muitas vezes sem discurso articulado sobre o assunto, defendem esse direito na prática, na teimosia de voltar após ter sido expulso, seja pagando aluguel ou ocupando casarões, ou na teimosia de não deixar suas casas, apesar de todas as ameaças. Para toF्? dos eles, os "bairros" são sinônimos de distânN cia, violência, isolamento e tédio. Referindo-se $\stackrel{8}{i}$ ao bairro de Suçuarana, Rita, uma interlocutora do antropólogo John Collins, na década de 1990, foi enfática: "Não há nada para mim ali. Só tédio. E morte” (Collins, 2008, p. 293). E é sempre para os bairros distantes que os prograi. की

${ }^{9}$ Disponível em https://www.facebook.com/articulacaodocentroantigodesalvador/ Página do Articulação do Centro Histórico, publicada no Facebook no dia 24 de junho de 2017 para consulta 26/06/2017. entre centro e periferia. Aberta ou silenciosamente, discursos e práticas são contrapolíticas espaciais que desafiam a regra que, no Brasil, dita que "o lugar dos trabalhadores pobres e o lugar para os trabalhadores pobres” é a periferia (Holston, 2013, p. 197). No caso dos casarões habitados com dignidade, trata-se de ainda mais: são experimentações de autogestão e liderança feminina. Ensaia-se, apesar de todas as dificuldades, com muito esforço e sacrifício, a invenção de um habitar com regras autônomas, que impede a entrada do tráfico de drogas e sua violência, um habitar onde os espaços coletivos e privados são igualmente cuidados e resguardados, onde a liderança feminina é afirmada e respeitada. Diante desses ensaios, o remanejamento de seus moradores - na verdade, de suas moradoras - para outros locais ou prédios não passa de uma aberta cegueira política.

Recebido para publicação em 07de novembro de 2017 Aceito em 13 de maio de 2019

\section{REFERÊNCIAS}

AMADO, J. Suor. São Paulo: Companhia das Letras, 2011. BACELAR, J. A família da prostituta. São Paulo: Ática, 1982.

. Levantamento sócio-econômico da área Norte do Pelourinho. Salvador: Fundação do Patrimônio Artístico e Cultural da Bahia, 1975.

BIRMAN, P.; FERNANDES, A.; PIEROBON, C. Um emaranhado de casos: tráfico de drogas, estado e precariedade em moradias populares. Mana, Rio de Janeiro, v. 3, n. 20, 2014

BITTENCOURT, J. M. Luta e resistência dos moradores pelo direito à moradia em áreas de patrimônio cultural: a formação de uma esfera pública. Salvador: Edufba, 2015.

CARDOSO, L. A. Entre vilas e avenidas. Habitação proletária em Salvador na Primeira República. 1991. Dissertação (Mestrado em Arquitetura e Urbanismo)Universidade Federal da Bahia, Salvador.

CERTEAU, M. A invenção do cotidiano. 16 ed. Rio de Janeiro: Vozes, 1994. (1. Artes de fazer).

COLLINS, J. "But what if I should need to defecate in your neihgborhood, madam?"Empire, redeption and "the tradition of the opressed in a brazilian world heritage site". Cultural Anthropology, [s.1], v. 23, n. 2, p. 279-328, May 2008. Disponível em: http://anthrosource. onlinelibrary.wiley.com/hub/issue/10.1111/cuan.2008.23. issue-2/. Acesso em: 14. 03. 2017.

COSTA, A. Ekabó! Trabalho escravo, condições de 
moradia e reordenamento urbano em Salvador no século XIX. 1989. Dissertação (Mestrado em Arquitetura e Urbanismo)- Universidade Federal da Bahia, Salvador.

DAVID, O. O inimigo invisível. Epidemia na Bahia no século XIX. Salvador: Edufba; Sarah Letras, 1996.

ESPINHEIRA, C. G. Comunidade do Maciel. Salvador Fundação do Patrimônio Artístico e Cultural da Bahia, 1971.

FARIAS, J. et al. Cidades negras. Africanos, crioulos e espaços urbanos no Brasil escravista do século XIX. 2 ed. São Paulo: Alameda, 2008.

FREYRE, G. Sobrados e mucambos. Decadência do patriarcado rural e desenvolvimento do urbano. São Paulo: Global Editora, 2004.

GONÇALVES, A. M. Um defeito de cor. Rio de Janeiro, São Paulo: Record, 2009. Disponível em: file://C:/Users/ URPI/Downloads/Um\%20Defeito\%20de\%20Cor\%20-\%20 Ana\%20Maria\%20\%20Goncalves.pdf. Acesso em: 23.02. 2017.

GORDILHO, A. Limites do habitar. Segregação e exclusão na configuração urbana contemporânea de Salvador e perspectivas no final do século XX. 2 ed. Salvador: Edufba, 2008.

GOTTSCHALL, C.; SANTANA, M., ROCHA, A. G. Perfil dos moradores do centro tradicional de Salvador à luz do Censo de 2000. In: GOTTSCHALL, C.; SANTANA, M. (Org.) Centro da cultura de Salvador. Salvador: Edufba: 2006.

GOVERNO DO ESTADO DA BAHIA, COMPANHIA DE DESENVOLVIMENTO DA REGIÃO METROPOLITANA DE SALVADOR (CONDER). Uso do solo do centro histórico de Salvador. Salvador: IPAC, 1997-1998.

HEIDEGGER, M. Construir, habitar, pensar. 1954. Disponível em: http://www.prourb.fau.ufrj.br/jkos/p2/ heidegger construir,\%20habitar,\%20pensar.pdf. Acesso em: 27. 03. 2016

HOLSTON, J. Cidadania insurgente. Disjunções da democracia e da modernidade no Brasil. São Paulo: Companhia das Letras, 2013.

INGOLD, T. The perception of the ambience. Essays on livelihood, dwelling and skill. London: Routledge, Taylor \& Francis e-Library, 2002

KOVARICK, L. Viver em risco. Sobre a vulnerabilidade socioeconômica e civil. São Paulo: 34, 2009.

KULICK, D. Travesti. Prostituição, sexo, gênero e cultura no Brasil. Rio de Janeiro: Fiocruz, 2008.
MATTOSO, K. Q. de. Bahia, século XIX: uma província no Império. 2 ed. Rio de Janeiro: Nova Fronteira, 1992.

MIRANDA, L. C. Vizinhos do (in)conformismo: o movimento dos sem teto da Bahia entre a hegemonia e a contra-hegemonia. 2008. Dissertação (Mestrado em Ciências Sociais) - Universidade Federal da Bahia, Salvador.

MONTOYA URIARTE, U. Entra em beco, sai em beco. Formas de habitar o centro, Salvador e Lisboa. Salvador: Edufba, 2019

Intervenções recentes em centros históricos: as políticas de "recuperação" dos centros históricos de Salvador, Lima e Quito. Cadernos do CEAS, Salvador, p. 73-92, nov./dez, 2003.

Pobreza e cultura. A luta dos pobres para permanecer morando no centro histórico de Salvador. Cadernos PPG-AU/FAUFBA, v. 10, p. 1-20, Salvador, 2012.

PIRES, T. C.; SOUZA, C. Habitação social no Centro Antigo de Salvador: avanços e projetos. In: Companhia de Desenvolvimento Urbano do Estado da Bahia (CONDER).

Centro Antigo de Salvador. Plano de Reabilitação Participativo: Avanços. Salvador: CONDER/DIRCAS, 2014.

SANTOS, E. et al. Atlas sobre o direito de morar em Salvador. Salvador: Edufba, 2012.

SANTOS, M. O centro da cidade do Salvador. Estudo de geografia urbana. Salvador: Universidade Federal da Bahia; Livraria Progresso, 1959.

SECRETARIA DE EDUCACÃO E CULTURA DO ESTADO DA BAHIA. FUNDACÃO DO PATRIMÔNIO ARTISTICO E CULTURAL DA BAHIA. Levantamento Sócio-Econômico do Pelourinho. Pesquisa dirigida por Vivaldo da Costa Lima e patrocinada pela Superintendência de Turismo da Cidade do Salvador. Salvador, 1969.

SENRA, R. Assim se vive nas ocupações urbanas de SP. Disponível em: http://outras-palavras.net/ outrasmidias/?p=119276, 13 de março de 2015. Acesso em: 15. 03. 2015.

SIMÕES, M. L.; MOURA, M. De quem é o centro histórico de Salvador? Cadernos do CEAS, Salvador, n. 96, 1986.

WISSENBACH, M. C. Da escravidão à liberdade: dimensões de uma privacidade possível. In: SEVCENKO, N. (Org.) História da vida privada no Brasil 3. República: da Belle Époque à era do rádio. São Paulo: Companhia das Letras, 1998.

ZALUAR, A. A máquina e a revolta. As organizações populares e o significado da pobreza. São Paulo: Brasiliense, 1985. 


\section{TO INHABIT OCCUPIED MANSIONS IN THE HISTORICAL CENTER OF SALVADOR, BAHIA, BRAZIL: old collective houses and new experiences and rights}

\author{
Urpi Montoya Uriarte
}

The objective of this article is to describe, analyze and reflect about a modality of housing that has been gradually gaining quantitative and qualitative importance in the city of Salvador (Bahia, Brazil) and in its historical center (CHS). These are the occupations of old houses and buildings by poor people, linked to the homeless movements. The ethnographic field work carried out with six occupations allowed me to arrive at some conclusions that I present in this work: 1) that some occupations are an updated version of the old "cortiços" of CHS, with problems that aggravate their situation even more; 2) that most of them are essays on a new way of living which represents a rich experience of self-management and female leadership; 3) that centrality is an essential value for precarious and vulnerable workers who have been living in the center of the city since the nineteenth century, a value that is now being claimed in discourses and / or practices such as the right to centrality.

Key wORDS: Occupations. Historical Center of Salvador (CHS). Collective housing. Ways of dwelling. Centrality.

\author{
HABITER DES MANOIRS OCCUPES DANS LE \\ CENTRE HISTORIQUE DE SALVADOR, BAHIA, \\ BRESIL: anciens logements colletifs et nouvelles \\ expériences et droits
}

Urpi Montoya Uriarte

L'objectif de cet article est décrire, analyser et réfléchir sur une modalité de logement qui a progressivement gagné en importance quantitative et qualitative dans la ville de Salvador (Bahia, Brésil) et dans son centre historique (CHS). Ce sont les occupations des vieilles maisons et des bâtiments par les pauvres, liées aux mouvements des sans-abri. Le travail de terrain ethnographique mené avec six occupations m'a permis d'arriver à quelques conclusions que je présente dans ce travail: 1) que certaines occupations sont une version actualisée des anciens "cortiços" du CHS, avec des problèmes qui aggravent encore leur situation; 2) que la plupart d'entre eux sont des essais sur un nouveau mode de vie qui représente une riche expérience d'autogestion et de leadership féminin; 3) que la centralité est une valeur essentielle pour les travailleurs précaires et vulnérables qui vivent dans le centre-ville depuis le XIXe siècle, une valeur qui est maintenant revendiquée dans les discours et / ou les pratiques telles que le droit à la centralité.

of Mots CLÉs: Occupations. Centre Historique de of Salvador (SHC). Logement collectif. Façons d’habiter. Centralité. Universidade Federal da Bahia. Professora permanente do Programa de Pós-Graduação em Antropologia da Universidade Federal da Bahia. Coordena o Núcleo de Pesquisa Panoramas Urbanos, desenvolvendo pesquisas na área de Antropologia urbana Suas mais recentes publicações são: Entra em Beco, sai em beco: formas de habitar o centro, Salvador e Lisboa" (Edufba 2019); Avenida Sete: Antropologia e urbanismo no centro de Salvador" (Edufba 2017). 